\title{
Multiple pathogens in adult patients admitted with community-acquired pneumonia: a one year prospective study of 346 consecutive patients
}

\author{
David Lieberman, Fransisc Schlaeffer, Ida Boldur, Devora Lieberman, Shula Horowitz, \\ Maureen G Friedman, Maija Leiononen, Ora Horovitz, Esther Manor, Avi Porath
}

\section{Division of Internal Medicine \\ David Lieberman \\ F Schlaeffer \\ Devora Lieberman \\ A Porath}

National Center for Mycoplasma

$S$ Horowitz

Virology Unit

M G Friedman

E Manor

Soroka Medical Center of Kupat Holim,

Faculty of the Health

Sciences, Ben-Gurion

University of the

Negev, Beer-Sheva,

Israel 84101

Department of Microbiology, Assaf Harofe Medical Center, Zerifin, Israel I Boldur

National Public Health Institute, Oulu, Finland

$M$ Leinonen

Savyon Diagnostics Laboratories, Ashdod, Israel

O Horovitz

Correspondence to: Dr David Lieberman.

Received 3 April 1995 Returned to authors 24 July 1995

Revised version received 14 August 1995

Accepted for publication 25 September 1995

\begin{abstract}
Background - The purpose of this study was to assess the causes of communityacquired pneumonia in adult patients admitted to hospital.

Methods - A prospective study was performed on 346 consecutive adult patients (54\% men) of mean (SD) 49.3 (19.5) years (range 17-94) admitted to a university affiliated regional hospital in southern Israel with community-acquired pneumonia over a period of one year. Convalescent serum samples were obtained from 308 patients $(89 \%)$. The aetiological diagnosis for community-acquired pneumonia was based on positive blood cultures and/or significant changes in antibody titres to Streptococcus pneumoniae, Haemophilus influenzae, Moraxella catarrhalis, respiratory viruses, Coxiella burnetii, Mycoplasma pneumoniae, Chlamydia pneumoniae, and Legionella sp.

Results - The aetiology of communityacquired pneumonia was identified in 279 patients $(80 \cdot 6 \%)$. The distribution of causal agents was as follows: $S$ pneumoniae, 148 patients $(42 \cdot 8 \%) ; M$ pneumoniae, 101 (29.2\%); C pneumoniae, 62 (17.9\%); Legionella sp, 56 (16.2\%); respiratory viruses, 35 (10.1\%); C burnetii, 20 (5.8\%); H influenzae 19 (5.5\%); and other causes, 21 patients $(6 \cdot 0 \%)$. In patients above the age of 55 years $C$ pneumoniae was the second most frequent aetiological agent $(25 \cdot 5 \%)$. In 133 patients $(38 \cdot 4 \%)$ more than one causal agent was found.

Conclusions - The causal agents for community-acquired pneumonia in Israel are different from those described in other parts of the world. In many of the patients more than one causal agent was found. In all these patients treatment should include a macrolide antibiotic, at least in the first stage of their illness.

(Thorax 1996;51:179-184)
\end{abstract}

Keywords: community-acquired pneumonia, aetiology, epidemiology, Israel

Community-acquired pneumonia is a common and important cause of admission to hospital, and presents a challenge to physicians who must decide upon specific therapy without the benefit of a definitve aetiological diagnosis. In order to reach logical therapeutic decisions physicians need reliable data on the relative prevalence of different aetiological agents in the patient's area of residence, in addition to the clinical, laboratory, and radiological findings. The relative frequency of aetiological agents varies among different geographical regions. ${ }^{1}$

In view of the objective difficulties in determining an exact aetiology for communityacquired pneumonia, even in retrospect, reviews on this subject have been influenced by the broad range of laboratory techniques used to diagnosis the disease and to identify the causative agent. The diagnostic difficulties have been compounded by the discovery of new pathogens such as Legionella $\mathrm{sp}^{2}$ and, recently, Chlamydia pneumoniae, ${ }^{3}$ adding to the list of frequent causes of community-acquired pneumonia.

We have conducted a prospective study of the prevalence of causal agents in all adult patients admitted with community-acquired pneumonia during one year to the Soroka Medical Center in Beer-Sheva, Israel. In order to make the best use of advanced serological laboratory techniques, a concerted effort was made to obtain convalescent serum samples from most of the patients.

The Soroka Medical Center in Beer-Sheva is located in a city of 150000 residents in the south of Israel. It serves a population of 300000 inhabitants of the Negev region, a semi-arid desert area mostly at sea level. Average temperatures during the study year ranged from $27^{\circ} \mathrm{C}$ in the summer to $9^{\circ} \mathrm{C}$ in the winter. The average yearly rainfall (which falls exclusively during the winter) is $200 \mathrm{~mm}$.

\section{Methods}

PATIENTS

A prospective study of the causes of community-acquired pneumonia was conducted in 346 adult patients admitted between 1 November 1991 and 31 October 1992. The study was approved by the review board for human research (the Helsinki committee) of the Soroka Medical Center and all patients gave their informed consent to participate.

The mean (SD) age of the patients was $49 \cdot 3$ (19.5) years (range 17-94). One hundred and 
eighty seven patients (54\%) were men. Sixteen patients $(4.6 \%)$ died in hospital. All other patients were alive at least six weeks after admission. During the course of their hospital stay the patients were diagnosed and treated by the medical staff of the internal medicine wards without intervention by the investigators. At discharge the patients were referred to the investigators at the outpatient clinic of the hospital for follow-up.

Community-acquired pneumonia was considered to be present by an acute febrile illness with a new pulmonary infiltrate on the chest radiograph, and a clinical and radiological course that confirmed the diagnosis. Exclusion criteria included a positive blood test for HIV, lung malignancy and patients who had been discharged from hospital within the preceding 21 days.

\section{SERUM SAMPLES}

In addition to routine hospital blood tests, a serum sample was obtained within the first 48 hours of admission for serological testing. A second (convalescent) serum sample was obtained from 308 patients ( $89 \%$ ) usually at the follow up appointment. The mean interval between the two serum samples was $31 \cdot 7(12 \cdot 1)$ days (range 17-45). All serum samples were separated immediately and stored at $-70^{\circ} \mathrm{C}$ until tested.

\section{SEROLOGICAL TESTS AND CAUSAL DIAGNOSES}

The diagnosis of bacterial pathogens was based on positive blood cultures and/or positive serological tests. In patients with a positive blood or pleural fluid culture the isolated bacterium was considered to be the causative agent of the community-acquired pneumonia. In order to identify possible bacterial pathogens in patients with negative blood cultures we tested 308 pairs of serum for the presence of specific antibodies to Streptococcus pneumoniae pneumolysin, Haemophilus influenzae, and Moraxella (Branhamella) catarrhalis. IgG antibodies to pneumococcal protein toxin, pneumolysin, were measured by enzyme immunoassay (EIA) using pneumolysin produced in Bacillus subtilis as antigen. ${ }^{4}$ A twofold or greater rise in antibody titre between paired serum samples was considered diagnostic for $S$ pneumoniae infection. ${ }^{45}$ Total antibodies to unencapsulated $H$ influenzae ${ }^{6}$ and $M$ catarrhalis ${ }^{78}$ were measured by EIA using whole bacterial cells of respective bacteria as antigens. A rise in antibody titre of $\geqslant 3$ between paired serum samples was considered diagnostic.

$S$ pneumoniae specific immune complexes were determined in all 654 (paired and unpaired) serum samples by measuring antibodies to pneumolysin and to the mixture of 23 capsular polysaccharides present in the vaccine, from precipitated and redissolved immune complexes. $^{910}$ The cut-off value for the presence of $S$ pneumoniae immune complexes was based on results of serum samples from 40 healthy elderly people (mean $\pm 2 S D$ ). All bacterial serological tests were conducted at the
Finnish National Public Health Institute in Helsinki and in Oulu, Finland.

Community-acquired pneumonia was considered to be caused by $S$ pneumoniae if there was a positive culture for $S$ pneumoniae (blood or pleural fluid) or a positive serological diagnosis based on pneumolysin antibodies or the presence of $S$ pneumoniae specific immune complexes as detailed above; it was considered to be due to $H$ influenzae or $M$ catarrhalis in the presence of a positive blood culture or positive serology.

$M$ pneumoniae was diagnosed as the causal agent by two different serological methods using commercial kits. Both tests were performed on all 654 serum samples. The antibody titre was determined by microparticle agglutination using the commercial kit SerodiaMyco II (Fujirebio, Japan). Using this method, $M$ pneumoniae was diagnosed if there was a fourfold increase in antibodies in the paired serum samples and/or an antibody titre of at least $1: 160$ in at least one serum sample. ${ }^{11}$ The antibody titre for $M$ pneumoniae was also determined by the antibody capture enzyme immunoassay method using the commercial kit Sero $M$ pneumoniae test kit (Diatech Diagnostics, Israel). In this method $M$ pneumoniae was diagnosed if $\operatorname{IgM}$ antibodies were present in at least one serum sample, or if there was evidence of seroconversion or a significant increase in $\operatorname{IgG}, \operatorname{IgM}$, or $\operatorname{IgA}$ between the two serum samples. $M$ pneumoniae was considered the aetiological agent for community-acquired pneumonia in patients who were positive for $M$ pneumoniae in at least one of the two serological tests.

$C$ pneumoniae as the cause of communityacquired pneumonia was determined by the microimmunofluorescence method utilising $C$ pneumoniae elementary bodies (Washington Research Foundation, USA, and Kajaani 6, Finland) as antigen to detect IgG, IgA, and IgM antibodies specific to $C$ pneumoniae. A fourfold or greater increase in titre for any immunoglobulin class between paired serum samples, an IgG titre of $\geqslant 512$, an IgA titre of $\geqslant 64$, or an IgM titre of $\geqslant 16$ was considered presumptive evidence that $C$ pneumoniae was the cause of community-acquired pneumonia. ${ }^{12}$

Serological testing for $C$ burnetii was performed using a commercial kit based on indirect microimmunofluorescence (INDX, Integrated Diagnostics Inc, Baltimore, Maryland, USA). $C$ burnetii was considered to be the causal agent for community-acquired pneumonia in the presence of a fourfold or greater increase in IgG titres between paired serum samples or a positive test for IgM in a single dilution of $1: 80$.

Antibodies to 21 different serogroups of $\mathrm{Le}$ gionella bacteria were detected using the indirect immunofluorescence test. Formalin fixed Legionella bacteria served as antigens. Legionella $\mathrm{sp}$ was considered to be the causal agent of community-acquired pneumonia in the presence of a fourfold or greater increase in IgG between paired serum samples or if the IgM titre was $\geqslant 64$. 
Table 1 Number (\%) of cases of community-acquired pneumonia by cause and age group

\begin{tabular}{|c|c|c|c|c|c|c|c|}
\hline \multirow[b]{2}{*}{ Aetiology } & \multirow[b]{2}{*}{ Total } & \multicolumn{5}{|l|}{ Age (years) } & \multirow[b]{2}{*}{ Mean (SD) age } \\
\hline & & $17-44$ & $45-54$ & $55-64$ & $65-74$ & $75+$ & \\
\hline $\begin{array}{l}\text { All } \\
S \text { pneumoniae } \\
H \text { influenzae } \\
M \text { catarrhalis } \\
\text { Other bacteria* } \\
M \text { pneumoniae } \\
C \text { pneumoniae } \\
C \text { burnetii (Q fever) } \\
\text { Legionella sp }\end{array}$ & $\begin{array}{l}346 \\
148(42 \cdot 8) \\
19(5 \cdot 5) \\
7(2 \cdot 0) \\
7(2 \cdot 0) \\
101(29 \cdot 2) \\
62(17 \cdot 9) \\
20(5 \cdot 8) \\
56(16 \cdot 2)\end{array}$ & $\begin{array}{l}162 \\
66(40 \cdot 7) \\
8(4 \cdot 9) \\
3(1 \cdot 9) \\
2(1 \cdot 2) \\
70(43 \cdot 2) \\
20(12 \cdot 3) \\
14(8 \cdot 6) \\
29(17 \cdot 9)\end{array}$ & $\begin{aligned} 39 & \\
19 & (48 \cdot 7) \\
1 & (2 \cdot 6) \\
1 & (2 \cdot 6) \\
-15 & (38 \cdot 5) \\
5 & (12 \cdot 8) \\
2 & (5 \cdot 1) \\
8 & (20 \cdot 5)\end{aligned}$ & $\begin{aligned} & 54 \\
& 16(29 \cdot 6) \\
& 6(11 \cdot 1) \\
& 2(3 \cdot 7) \\
& 2(3 \cdot 7) \\
& 8(14 \cdot 8) \\
& 13(24 \cdot 1) \\
& 2(3 \cdot 7) \\
& 8(14 \cdot 8)\end{aligned}$ & $\begin{aligned} 46 & \\
21 & (45 \cdot 6) \\
2 & (4 \cdot 3) \\
1 & (2 \cdot 2) \\
1 & (2 \cdot 2) \\
6 & (13 \cdot 0) \\
13 & (28 \cdot 3) \\
2 & (4 \cdot 3) \\
7 & (15 \cdot 2)\end{aligned}$ & $\begin{array}{l}45 \\
26(57 \cdot 8) \\
2(4 \cdot 4) \\
-2(4 \cdot 4) \\
2(4 \cdot 4) \\
11(24 \cdot 4) \\
-4(8 \cdot 8)\end{array}$ & $\begin{array}{l}49 \cdot 3(19 \cdot 5) \\
51.3(20 \cdot 6) \\
51 \cdot 2(18 \cdot 4) \\
50.9(13 \cdot 6) \\
59 \cdot 1(23 \cdot 0) \\
38.2(15 \cdot 1) \dagger \\
55.9(19 \cdot 0) \ddagger \\
41.1(14.0) \\
47.6(17 \cdot 8)\end{array}$ \\
\hline $\begin{array}{l}\text { Viruses } \\
\text { Influenza A } \\
\text { Influenza B } \\
\text { Parainfluenza 1 } \\
\text { Parainfluenza } 3 \\
\text { RSV } \\
\text { Adenovirus } \\
\text { Active tuberculosis } \\
\text { Unknown }\end{array}$ & $\begin{array}{c}8(2 \cdot 3) \\
10(2 \cdot 9) \\
5(1 \cdot 4) \\
4(1 \cdot 2) \\
5(1 \cdot 4) \\
5(1 \cdot 4) \\
7(2 \cdot 0) \\
67(19 \cdot 4)\end{array}$ & $\begin{array}{c}3(1 \cdot 9) \\
6(3 \cdot 7) \\
3(1 \cdot 9) \\
1(0 \cdot 6) \\
1(0 \cdot 6) \\
4(2 \cdot 5) \\
3(1 \cdot 9) \\
31(19 \cdot 1)\end{array}$ & $\begin{array}{l}1(2 \cdot 6) \\
1(2 \cdot 6) \\
1(2 \cdot 6) \\
2(5 \cdot 1) \\
- \\
\overline{3}(7 \cdot 7) \\
6(15 \cdot 4)\end{array}$ & $\begin{array}{c}1(1.9) \\
1(1.9) \\
-1(1.9) \\
2(3.7) \\
-1(1.9) \\
14(25.9)\end{array}$ & $\begin{array}{l}1(2 \cdot 2) \\
1(2 \cdot 2) \\
- \\
1(2 \cdot 2) \\
= \\
8(17 \cdot 4)\end{array}$ & $\begin{array}{c}2(4 \cdot 4) \\
1(2 \cdot 2) \\
1(2 \cdot 2) \\
-1(2 \cdot 2) \\
1(2 \cdot 2) \\
-9(20 \cdot 0)\end{array}$ & $\begin{array}{l}57 \cdot 0(26.1) \\
45.8(21.6) \\
46.8(21.5) \\
47.0(15.4) \\
68.8(9.0) 9 \\
44.0(17 \cdot 6) \\
41.3(13.4) \\
50.3(17.9)\end{array}$ \\
\hline Total & $532(153 \cdot 8)$ & $264(163 \cdot 0)$ & $65(166 \cdot 7)$ & $77(142 \cdot 6)$ & $64(139 \cdot 2)$ & $62(137 \cdot 8)$ & \\
\hline
\end{tabular}

* Non-pneumoniae streptococcus, Staphylococcus aureus, Acinetobacter, Pseudomonas aeruginosa.

$\dagger \mathrm{p}<0.0005, \ddagger \mathrm{p}<0.005, \S \mathrm{p}<0.05$ between mean age for this cause and mean age for all other causes.

Table 2 Number (\%) of cases of community-acquired pneumonia with multiple causes

\begin{tabular}{lc}
\hline No. of aetiologies & No. of patients (\%) \\
\hline 0 & $67(19 \cdot 4)$ \\
1 & $146(42 \cdot 2)$ \\
2 & $96(27 \cdot 7)$ \\
3 & $29(8 \cdot 4)$ \\
4 & $7(2 \cdot 0)$ \\
6 & $1(0 \cdot 3)$ \\
Total & $346(100)$ \\
\hline
\end{tabular}

Viral causes for community-acquired pneumonia were assessed by complement fixation for six common respiratory viruses (influenza $A$, influenza $B$, adenovirus, respiratory syncytial virus (RSV), parainfluenza 1, and parainfluenza 3) using commercial antigens (Virion Ltd, Cham, Switzerland). A viral cause for community-acquired pneumonia was determined if there was evidence of a fourfold or greater increase in antibody titres for a specific viral agent between paired serum samples.

Active pulmonary tuberculosis was defined as the presence of Mycobacterium tuberculosis in sputum.

\section{DATA ANALYSIS}

The $\chi^{2}$ test was used to determine the significance of differences in proportions between groups. Student's $t$ test was used to determine whether the means of continuous variables were significantly different.

\section{Results}

Table 1 shows the frequencies of the various causal agents for community-acquired pneumonia among the 346 patients, the age distribution, and mean ages for each cause. In all, the causal agent was identified in 279 patients $(80.6 \%)$. The commonest agent was $S$ pneumoniae which was identified in $148(42 \cdot 8 \%)$ of the patients, of whom $26(7 \cdot 5 \%)$ were bacteraemic. The next most common agent was $M$ pneumoniae which was found in 101 patients $(29 \cdot 2 \%)$, followed by $C$ pneumoniae in 62 patients $(17 \cdot 9 \%)$. The frequency of the other agents was $16 \cdot 2 \%$ for Legionella sp (56 patients), $10 \cdot 1 \%$ for respiratory viruses (35 patients, with evidence for simultaneous infection with two viruses in two patients), $5 \cdot 8 \%$ for $C$ burnetii (20 patients), $5.5 \%$ for $H$ influenzae (19 patients, including two with bacteraemia), and $2 \%$ for $M$ catarrhalis (seven patients). Seven other patients had evidence of other bacterial agents: four with non-pneumoniae streptococcus, one with Staphylococcus aureus, one with Acinetobacter sp, and one with Pseudomonas sp. Seven patients $(2 \%)$ had active pulmonary tuberculosis.

The commonest causal agent in younger patients (17-44 years of age) was $M$ pneumoniae (43.2\%) followed by $S$ pneumoniae $(40 \cdot 7 \%)$. In older age groups $S$ pneumoniae was the most common pathogen followed by $M$ pneumoniae in patients aged 45-54 years, and $C$ pneumoniae in patients above the age of 55 . In all age groups

Table 3 Distribution of associations between the various causes

\begin{tabular}{|c|c|c|c|c|c|c|c|c|c|c|c|}
\hline & $S$ pneumoniae & $H$ influenzae & $M$ catarrhalis & $\begin{array}{l}\text { Other } \\
\text { bacteria }\end{array}$ & $M$ pneumoniae & C pneumoniae & C burnetii & $\begin{array}{l}\text { Legionella } \\
\text { sp }\end{array}$ & Viruses & $\begin{array}{l}\text { Active } \\
\text { tuberculosis }\end{array}$ & $\begin{array}{l}\text { Single } \\
\text { cause* }\end{array}$ \\
\hline$S$ pneumoniae & - & & & & & & & & & & $48(32 \cdot 4)$ \\
\hline$H$ influenzae & 8 & - & & & & & & & & & $5(26 \cdot 3)$ \\
\hline$M$ catarrhalis & 3 & 2 & - & & & & & & & & $3(42.9)$ \\
\hline Other bacteria & 5 & $\overline{1}$ & 0 & - & & & & & & & $2(28 \cdot 6)$ \\
\hline M pneumoniae & 43 & 3 & 2 & 0 & - & & & & & & $36(35 \cdot 6)$ \\
\hline C pneumoniae & 34 & 4 & 2 & 1 & 12 & - & & & & & $19(30 \cdot 6)$ \\
\hline C burnetii & 10 & 1 & 0 & 0 & 6 & 1 & - & & & & $5(25 \cdot 0)$ \\
\hline Legionella $\mathrm{sp}$ & 23 & 2 & 0 & 2 & 15 & 12 & 1 & - & & & $21(37.5)$ \\
\hline Viruses & 17 & 4 & 1 & 0 & 10 & 5 & 0 & 3 & - & & $6(17 \cdot 1)$ \\
\hline Active tuberculosis & 6 & 0 & 0 & 0 & 3 & 1 & 0 & 1 & 1 & - & $1(14 \cdot 3)$ \\
\hline
\end{tabular}

* Percentage of all patients with this same cause. 
the third most common agent was Legionella sp. Patients with $M$ pneumoniae were significantly younger ( $\mathrm{p}<0.0005)$, and patients with $C$ pneumoniae and RSV significantly older $(\mathrm{p}<0.005$ and $\mathrm{p}<0.05$, respectively), than patients with other causes.

In all, we identified 532 different causal agents in 279 patients, implying a high rate of multiple causes. Table 2 shows the distribution of causes among the 346 patients. A single agent was found in 146 patients $(42 \cdot 2 \%$ of all patients and $52 \cdot 3 \%$ of patients with a causal diagnosis), while 2-6 agents were found in 133 patients (38.4\% and $47 \cdot 7 \%$, respectively).

Table 3 presents the rate of association between the different causal agents in patients with mixed infection, with the numbers and percentages of patients with single agents. All possible associations were found except for agents with particularly low frequencies.

\section{Discussion}

Our study is unique in several ways. The study population is one of the largest published ${ }^{1}$ and reflects a complete picture of all the causes of community-acquired pneumonia in adult patients admitted to a hospital in one region, covering all the seasons of the year. Our success in obtaining convalescent serum sample from $89 \%$ of the patients enabled us to establish a causal diagnosis for community-acquired pneumonia in $80.6 \%$ of the patients. This percentage is high even in comparison with previous studies with diagnoses for approximately $70 \% .^{13-16}$

Most of our diagnoses, including the bacterial pathogens, were based on serological testing. Studies in which serological tests are not used give an unrepresentative picture of the prevalence of the various infectious agents. A diagnostic serological test is generally indicative of an invasive infection and strengthens evidence for a causal relationship between the specific infectious agent and community-acquired pneumonia. ${ }^{17}$

We based the diagnosis of $M$ pneumoniae as the causal agent for community-acquired pneumonia on two tests using two different commercial kits utilising different serological methods. Of the 101 patients in whom $M$ pneumoniae was identified as the causal agent, $61(60.4 \%)$ were positive on both methods (microparticle agglutination and antibody capture enzyme immunoassay), six $(5 \cdot 9 \%)$ were positive by the first method and negative by the second, and $34(33.7 \%)$ were negative by the first method and positive by the second. In a paper in which we detailed and analysed these results we reached the conclusion that the two methods are complementary and therefore improve our diagnostic yield for this agent. ${ }^{18}$

In non-bacteraemic patients the causal diagnosis of $S$ pneumoniae community-acquired pneumonia was based on serological tests. The standard method using antibody response to pneumolysin is very reliable but the range of sensitivities is only $60-82 \%$ when paired serum samples taken two weeks apart are used, ${ }^{519}$ and it can only be used with paired samples. We therefore tested all serum (including unpaired samples) for antibodies to pneumolysin and capsular polysaccharides in circulating immune complexes. This method increased the sensitivity for identification of $S$ pneumoniae infection considerably. ${ }^{20}$ Our data do not enable us to determine the sensitivity and specificity of the serological tests for $S$ pneumoniae in the absence of a gold standard with which the results can be compared. An impression of the sensitivity of the tests can be gathered from the results of serological testing in the 26 patients with $S$ pneumoniae bacteraemia (22 of whom had paired serum samples). Sixteen of these 22 patients were positive when tested with pneumolysin antibodies. The pneumococcusspecific immune complexes test added positive results for another six patients so that, in all, 22 of the 26 patients were identified by these two serological methods.

The identification of $S$ pneumoniae infection as the leading cause for community-acquired pneumonia in our study is consistent with other studies. Our prevalence of $42 \cdot 8 \%$ is mid range in the broad spectrum of frequencies previously reported $(11 \cdot 5-76 \%) .{ }^{2122}$ Other causal agents have unusual frequencies in our study, particularly the high prevalence of infection with $M$ pneumoniae (29.2\%), C pneumoniae (17.9\%), and Legionella sp (16.2\%). The maximum prevalence rates reported in the literature for these pathogens were $22 \%,{ }^{1723} 12 \%,{ }^{24}$ and $15 \%,{ }^{22}$ respectively. We believe that the principal reasons for the high prevalence of infection by these three agents are regional epidemiological factors which are markedly different from those in other areas of the western world in which similar studies were conducted. However, the large number of paired serum samples in our study may also play an important part in these findings as the diagnosis of these three agents was based primarily on a rise in antibody titre and would not have been identified without the second serum sample. It is also possible that the distribution of causal agents identified for community-acquired pneumonia in other studies may have been similar to that reported here if more samples of convalescent serum had been obtained and sophisticated serological methods used.

Our most important result is the finding of multiple or mixed causes in 133 patients, representing $38.9 \%$ of the study population and $47 \cdot 7 \%$ of patients with definitive causal diagnoses. Many previous studies have also reported mixed causes. In some the percentage of mixed causes was about $10 \%$ of patients with community-acquired pneumonia, ${ }^{1415212526}$ usually with a viral and bacterial cause. In other studies, particularly those employing serological techniques to identify bacterial aetiologies, the rate of mixed causes ranges from $15 \cdot 8 \%,{ }^{27}$ through $21 \cdot 5 \%{ }^{19}$ and $24 \cdot 3 \%,{ }^{13}$ to $31 \%^{24}$ of all patients diagnosed in a group admitted with community-acquired pneumonia. The highest rate of mixed causes in adults admitted with community-acquired pneumonia was reported by Fransen $^{17}$ who found 183 patients with community-acquired pneumonia of mixed causes (43.6\% of cases with causal diagnoses) among 
598 patients. Taking into account that Fransen's study was published in 1970 , before Legionella sp and $C$ pneumoniae were identified, the rate of mixed causes in their study was higher than in ours. In all studies reporting a high rate of mixed causes, almost all possible combinations of causal agents have been identified. The other studies did not report details of the frequency distribution of the number of causes in each patient (table 2), but it would appear that a large percentage of patients had more than two causal agents.

As far as the possible role of mixed causes in the pathogenesis of community-acquired pneumonia is concerned, the contention of Lepow et $a l^{8}$ that "multiple simultaneous infections might be necessary for sufficient interference with pulmonary cleansing function to provide the appropriate setting for community-acquired pneumonia" is noteworthy. In this respect, several bacterial products can damage ciliated epithelial cells in the respiratory tract, ${ }^{29}$ and $M$ pneumoniae exerts a toxic effect on ciliated human epithelium. ${ }^{30}$ We have recently shown that $C$ pneumoniae induced ciliostasis in human bronchial epithelial cells. ${ }^{31}$ The injury to ciliary motility in epithelial cells by one infectious agent may establish the conditions for other infectious agents to infiltrate the lower respiratory tract.

The seven patients with active pulmonary tuberculosis were included in our study as they presented with an acute illness that met the inclusion criteria. Six of them had serological evidence for a concurrent infection with $S$ pneumoniae (table 2), and five had evidence of concurrent infection with an additional agent (one of these had two additional infectious agents). We were not able to exclude the possibility of false positive results due to cross reaction, particularly for $S$ pneumoniae. However, serological positivity represents a true causal association with the specific agent so the patients with tuberculosis had concurrent community-acquired pneumonia. It is possible that the patients had insidious tuberculosis and the acute community-acquired pneumonia brought them to the hospital, at which time their tuberculosis was also diagnosed. On the basis of our data we could not determine the clinical importance, if any, of the additional causal agent in patients with tuberculosis.

The results of our study have important practical implications for the initial treatment of adult patients admitted to hospital with community-acquired pneumonia in our region. During the course of the study, when the treating physicians were unware of the true causal diagnosis of the community-acquired pneumonia, most of the patients were treated with antibiotics from the $\beta$-lactam group and only about half were treated with erythromycin or tetracycline (approximately $20 \%$ were treated with a combination of antibiotics from these two groups). In light of the frequency distribution of causes found, and in particular the high prevalence of $M$ pneumoniae, Legionella $\mathrm{sp}$, and $C$ pneumoniae (the latter in elderly patients as well as younger ones), we believe that all patients with community-acquired pneumonia in our region should receive erythromycin or one of the newer macrolide antibiotics which are also effective in the treatment of $H$ influenzae. Alternatively, a combination of erythromycin with a second generation cephalosporin may be noted. This combination is recommended initially in patients with moderately severe or severe community-acquired pneumonia. The almost negligible prevalence of aerobic Gram negative bacilli in our study does not justify treating these patients with a third generation cephalosporin, or with $\beta$-lactam/ $\beta$-lactamase inhibitors. However patients who are severely ill should be given these medications early, together with a macrolide antibiotic.

1 Fang G, Fine M, Orloff J, Arisumi D, Yu VL, Kappor W, et al. New and emerging etiologies for community-acquired 69:307-16.

2 McDade JE, Shepard CC, Fraser DW, Tsai TR, Redus MA, Dowdle VJR, et al. Legionnaires' disease: isolation of a bacterium and demonstration of its role in other respiratory disease. $N$ Engl $₹$ Med 1977;297:1197-203.

3 Grayston JT, Campbell LA, Kuo C-C, Mordhorst $C H$, Saikku P, Thom DH, et al. A new respiratory tract pathogen: Chlamydia pneumoniae strain TWAR. $f$ Infect Dis 1990;161:618-25.

4 Jalonen E, Taira S, Paton JC, Kerttula Y, Suomalainen P, Leinonen M. Pneumolyzin produced in Bactillus subtilis as antigen for measurement of pneumococcal antibodies by enzyme immunoassay. Serodiagn Immunother Infect Dis 1990;4:451-8.

5 Jalonen E, Paton JC, Koskela M, Kerttula Y, Leinonen M. Measurement of antibody responses to pneumolysin - a promising method for the presumptive aetiological diagnosis $127-34$

6 Burman LA, Leinonen M, Trollfors B. Use of serological methods to diagnose pneumonia caused by noncapsulated Haemophilus influenzae and Moraxella catarrhalis. $\mathcal{F}$ Infect Dis 1994;170:220-2.

7 Leinonen M, Luotonen J, Herva E, Valkonen K, Makela $\mathrm{PH}$. Preliminary serologic evidence for a pathogenic role of Branhamella catarrhalis. $\mathcal{F}$ Infect Dis 1981;144:570-4.

8 Claesson B, Leinonen M. Moraxella (Branhamella) catarrhalis - an uncommon cause of community acquired pneumonia in Swedish children. Scand F Infect Dis 1994; 26:399-402.

9 Leinonen M, Syrjala H, Jalonen E, Kujala P, Herva E. Demonstration of pneumolysin antibodies in circulating immune complexes - a new diagnostic method for pneuimmune complexes - a new diagnostic method for pneumococcal pneum
1990;4:451-8.

10 Holloway Y, Snijder JA, Boersma WG. Demonstration of circulating pneumococcal immunoglobulin $G$ immune complexes in patients with community-acquired pneumonia by means of an enzyme-linked immunosorbent assay. $\mathcal{F}$ Clin Microbiol 1993;31:3247-54.

11 Echevarria JM, Leon P, Balfagon P, Lopez JA, Fernandez MV. Diagnosis of Mycoplasma pneumoniae infection by microparticle agglutination and antibody-capture enzyme20.

12 Ekman MR, Leinonen M, Syrjala H, Linnanmaki E, Kujala P, Saikku P. Evaluation of serological methods in the diagnosis of Chlamydia pneumoniae pneumonia during an diagnosis of Chlamydia pneumoniae pneumonia during an
epidemic in Finland. Eur $\mathcal{F}$ Clin Microbiol Infect Dis 1993; epidemic in

13 Ortquist A, Hedlund J, Grillner L, Jalonen E, Kallings I, Leinonen $\mathrm{M}$, et al. Aetiology, outcome and prognostic factors in community-acquired pneumonia requiring hospitalization. Eur Respir f 1990;3:1105-13.

14 Research Committee of the British Society and the Public Heath Laboratories Service. Community acquired pneumonia in adults in British hospitals in 1982-1983: a survey of the aetiology, mortality, prognostic factors, and outcome. $Q F$ Med 1987;62:195-222.

15 Holmberg $\mathrm{H}$. Aetiology of community-acquired pneumonia in hospital patients. Scand $\mathcal{F}$ Infect Dis 1987;19:491-501.

16 Levy M, Dromer F, Brion N, Leturdu F, Carbon C. Community-acquired pneumonia: importance of initial nonmunity-acquired pneumonia: importance of initial non-
invasive bacteriologic and radiographic investigations. invasive bacteriologic
Chest 1988;92:43-8.

17 Fransen $\mathrm{H}$. Clinical and laboratory studies on the role of viruses, bacteria, Mycoplasma pneumoniae, and Bedsonia in acute respiratory illness. Scand $\mathcal{F}$ Infect Dis 1970;2(Suppl 1): $1-38$.

18 Lieberman D, Lieberman D, Horowitz S, Horovitz O, Schlaeffer F, Porath A. Microparticle agglutination versus antibody-capture enzyme immunoassay for diagnosis of community-acquired Mycoplasma pneumoniae pneumonia. Eur $\mathcal{F}$ Clin Microbiol Infect Dis 1995;14:577-84. 
19 Kertulla Y, Leinonen M, Koskella M, Makela PH. The aetiology of pneumonia. Application of bacterial serology and basic laboratory methods. $\mathcal{f}$ Infect 1987;14:21-30.

20 Leinonen M, Syrjala H, Jalonen E, Kujala P, Herva E. Demonstration of pneumolyzin antibodies in dissociated immune complexes - a new method for etiological diagnosis of pneumococcal pneumonia. Serodiagn Immunother Infect Dis 1990;4:459-68.

21 White RJ, Blainey AD, Harrison KJ, Clarke S. Causes of pneumonia presenting to a district general hospital. Thorax 1981;36:566-70.

22 Macfarlane JT, Finch RG, Ward MJ, Macrae AD. Hospital study of adult community-acquired pneumonia. Lancet 1982;ii: $255-8$.

23 Lehtomaki K, Leinonen M, Takala A, Hovi T, Herva E, Koskela $M$. Etiological diagnosis of pneumonia in military conscripts by combined use of bacterial culture and serological methods. Eur 7 Clin Microbiol Infect Dis 1988;7: logical met.

24 Grayston JT, Kuo C-C, Wang S-P, Altman J. A new Chlamydia psittaci strain, TWAR isolated in acute respiratory tract infections. $N$ Engl $\mathcal{F}$ Med 1986;315:161-8.
25 Burman LA, Trollfors, B., Andersson B, Hendrichsen J, Juto $\mathrm{P}$, Kallings I, et al. Diagnosis of pneumonia by cultures, bacterial and viral antigen detection tests, and serology with special reference to antibodies against pneumococcal antigens. F Infect Dis 1991;163:1087-93.

26 Woodhead MA, Macfarlane JT, McCracken JS, Rose DH, Finch RG. Prospective study of the aetiology and outcome of pneumonia in the community. Lancet 1987; i:671-4.

27 Berntsson E, Blomberg J, Lagergard T, Trollfers B. Etiology of community-acquired pneumonia in patients requiring hospitalization. Eur $\mathcal{f}$ Clin Microbiol 1988;4:268-72.

28 Lepow ML, Balassanian N, Emmerich J, Roberts RB, Rosental M, Wolinsky E. Interrelationships of viral, mycoplasmal and bacterial agents in uncomplicated pneumycoplasmal and bacterial agents in uncomp

monia. Am Rev Respir Dis 1968;97:533-45.
29 Wilson R, Roberts D, Cole P. Effect of bacterial products on human ciliary function in vitro. Thorax $1985 ; 40: 124-31$.

30 Collier AM, Clyde WA. Relationships between Mycoplasma pneumoniae and human respiratory epithelium. Infect Immun 1977;3:694-701.

31 Shemer-Avni Y, Lieberman D. Chlamydia pneumoniae induced ciliostasis in ciliated bronchial epithelial cells. $\mathcal{f}$ Infect Dis 1995;171:1274-8. 